That his emphasis on the medical utility of his work did not impair the meticulousness of his philological preparations and the precision of his translation methods is the main reason why his translations are still celebrated as the crowning achievement of the Greek-Arabic translation movement.

This fortuitous combination of accessibility and accuracy was probably also one of the reasons why the translations of the Hunayn workshop, among them the present text, became key sources for Arabic medical scholars. Galen's commentaries on the Hippocratic Epidemics in particular were widely studied and quoted and it inspired a rich literature of commentaries, compilations, handbooks and teaching manuals.

The most important secondary works that quote the commentary and were instrumental in reconstructing the text of the translation have been described above. ${ }^{1}$ Galen's commentary not only served as an indispensable source for medical information; the embedded Hippocratic case descriptions also became a model for a genre of similar texts, starting with the famous case histories of al-Rāzî, ${ }^{2}$ especially in the aforementioned Comprehensive Book and in the oldest and largest collection of case histories, his Casebook (Kitāb al-tağārib). ${ }^{3}$

The study of the impact of Galenic and Hippocratic writings in general and the present text in particular is still at an early stage. ${ }^{4}$ Many Arabic medical writings remain unedited; with increasing availability, we shall be in a better position to reconstruct the reception of Galenic medical knowledge in Arabic. Recent studies and editions of medical texts already suggest that we can anticipate rich new findings from these sources: concepts drawn from Galen's commentary continued to reappear in different configurations in a wide variety of medical writings originating in the farthest reaches of the Muslim world. ${ }^{5}$

\title{
C. Editorial conventions
}

\section{The Arabic edition}

As a result of the small number of primary sources for the present text, the critical apparatus of this edition takes a somewhat different form from the customary negative notation of CMG editions. Instead of recording only those witnesses

1 These and other secondary works inspired by and quoting Galen's commentary were surveyed by Hallum, The Arabic Reception.

2 On Hippocratic and Galenic case histories as model for al-Rāzì’s case descriptions, cf. C. Álvarez Millán, Graeco-Roman Case Histories and their Influence on Medieval Islamic Clinical Accounts, Social History of Medicine 12, 1999, p. 19-43, esp. p. 34-42.

3 C. Álvarez Millán, Practice versus Theory: Tenth-century Case Histories from the Islamic Middle East, Social History of Medicine 13, 2000, p. 293-306.

4 On the reception of the Hippocratic corpus, cf. U. Weisser, Das Corpus Hippocraticum in der arabischen Medizin, in: Die hippokratischen Epidemien, p. 377-407.

5 Cf. e.g. S. Gigandet, Trois Maqālāt au sujet des épidémies de peste en Andalousie et au Maghreb, Arabica 48, 2001, p. 401-407 and Trois 'Maqāāāt' sur la prévention des épidémies, Arabica 52, 2005, p. 254-293 on a collection of fourteenth-century treatises from Andalusia and the Maghrib on the plague and its prevention. 
that differ from the main text, the present edition employs a positive apparatus that documents the text of all primary sources whenever variants occur. We think that this format is warranted because only a single primary witness (E) preserves the entire text of the commentary while all others only have certain parts, for example only the Hippocratic lemmata (A and P) or excerpts from both lemmata and Galen's comments (Ibn Riḍwān, Useful Passages). A positive apparatus allows the reader to determine exactly which primary witnesses attest to a word or passage.

A second difference between the present volume and other editions published in this series concerns the terminology of the apparatus. In Greek editions the terms correxi, scripsi and conieci denote progressively more significant editorial interventions in the edited text. To accommodate the somewhat different requirements of editing Arabic-language sources, we have reserved the term scripsi for corrections that exclusively affect the dotting of Arabic words while using correxi and conieci to signal interventions that affect the consonantal skeleton (rasm). The former denotes a correction of a single consonant or of otherwise very obvious scribal lapses, the latter a correction of more than one consonant or of textual problems that involve some degree of speculation on our part.

As mentioned above, the nature of the Arabic manuscript sources has complicated the reconstruction of the text. Most notable are the sparse, inconsistent and often erroneous dotting of letters and the virtual absence of vowel signs and hamza. In the interest of presenting a uniformly readable Arabic text its orthography has been normalised. This includes the placement of hamza and any required corrections of its kursi as well as the restoration of $y \vec{a} \overrightarrow{~ r e p r e s e n t i n g ~ a l i f ~}$ where the scribe used straight alif. In addition, since reporting each instance of absent diacritical dots and hamza in the manuscripts and recording all differences of this kind between manuscripts would have required a separate volume of notes, the apparatus focusses on those phenomena that seem most informative to the reader.

As a general rule the apparatus reports every variant in the rasm of a word. Where the undotted or incompletely dotted rasm of a manuscript reading is compatible with the reading presented in the main text, it is assumed to support it. Variant manuscript readings supplied in the apparatus give the actual (undotted or falsely dotted) readings of these manuscripts including, where present, any short vowels. Where the difference between the sources consist solely in variant dotting, it has only been recorded when it results in meaningful variants.

In addition to limited dotting and the virtual absence of hamza, all manuscripts display a fair share of typical scribal oversights. As long as they do not affect the meaning of the text, they have been silently corrected. Among them are for example errors in dotting imperfect verbal forms with an identical rasm which result in shifts between third person singular masculine, feminine and first person plural forms. The scribe of E sometimes omitted the suffixed silent alif of third person plural masculine perfect verb forms or (conversely) added hypercorrect alif after third person masculine singular perfect forms of verba ultimae wāw.

We have refrained from correcting some inconsistencies in grammatical congruence that all manuscripts display. The degree of variation between the manuscripts and frequent obvious cases of carelessness in the congruence of, for example, verbs and nouns or nouns on the one hand and demonstratives on the other makes 
it in fact very difficult to distinguish between scribal lapses and conscious choices by the translator. A case in point are two feminine nouns which an inattentive copyist may sometimes interpret as masculine. These terms - näfid ("shivering fits") and $\operatorname{sinn}$ ("age”) - are sometimes referred to with feminine demonstrative and relative pronouns and combined with feminine verbal forms; at other times the scribes switch to masculine references. Preferences differ across manuscripts: näfid ("shivering fits"), consistently read as masculine by the scribe of $\mathrm{P}$, is mostly interpreted as feminine in the first two and most of the third part of the Commentary on Book 1 in E and A. It is only combined with masculine verb forms when at least one other word intervenes between verb and noun or where the verb refers to a list of diseases or symptoms, some of which are masculine and some feminine. This seems to change starting with lemma III 22 (p. 452,9-456,5): in this and the following case histories and in Galen's explanations the noun näfid ("shivering fits") is combined with masculine verb forms, mostly așāba, "(he) had" or "(he) was affected by", and occasionally also masculine demonstrative and relative pronouns and adjectives.

Proper names have been normalised to their most frequent form but the apparatus records divergent forms exactly as they appear in each manuscript. For example, the scribe of E consistently transcribed the name Hippocrates as Abuqrāt but there are three instances in the Prooemium (p. 74,10, 76,3 and 78,9) where he omitted the inital alif and wrote Buqrăt. These cases have been normalised but also noted in the apparatus.

The few Islamic doxologies or pious insertions found at the beginning or end of each part of the Commentary on Book 1, which are unlikely to have been part of the original translation prepared by Hunayn ibn Ishạa, are athetised in square brackets and omitted from the English translation.

To facilitate reading the Arabic text, punctuation and paragraphing that follows the sense of the text and allows for easier comparison between text and translation have been added. Quotations in Galen's comments from this text and from other writings are marked with guillemets.

In addition to variants between the Arabic sources, the critical apparatus also documents sections of the Greek text that are not found in the Arabic translation. They are noted as "hab. Gr." and include references to the page and line of the Wenkebach edition. In some cases where the Greek text supports a reading or conjecture in the Arabic text, the apparatus refers to the relevant Greek readings. The manuscript sigla correspond to those introduced by Wenkebach; ${ }^{1}$ the siglum Gr. ${ }^{\omega}$ (the consensus of the Greek tradition) is used for quoted words or phrases for which all of Wenkebach's sources agree and his apparatus does not note any variants.

As explained above, the critical apparatus for the present text also notes variants from the secondary tradition. Their use has necessarily been selective because they often paraphrase or summarise Galen and are therefore of limited value for the reconstruction of the Arabic text. To allow the reader to distinguish between more or less close parallels in these sources, verbatim or near verbatim quotations are introduced in the similia apparatus with " $v$." (vide), non-verbatim quotations with "f." (confer). Variants from these secondary sources are reported in the critical 
apparatus only when they quote Galen's commentary reasonably closely and clearly refute or confirm readings. If the apparatus does not show any variants, it does not imply that the secondary sources listed in the similia apparatus confirm the reading of the text.

Our most important secondary source is Ibn Riḍwān's collection of excerpts, the Useful Passages. It consists almost entirely of verbatim or almost verbatim excerpts from the Arabic translation of the commentary and has therefore been used as a primary witness. Since he sometimes slightly redacted his excerpts, not all textual differences have been entered into the apparatus.

The present edition focuses on the Arabic translation rather than the Greek source text. The apparatus of parallel texts therefore does not reproduce the Greek testimonia, which are comprehensively documented in the apparatus of the Wenkebach edition. For a number of essential writings which Galen regularly quotes, for example the Hippocratic Aphorisms, Prognostic and Nature of Man, existing edited Arabic translations have been consulted and entered into the apparatus of parallel texts together with their Greek counterparts. The latter include the Littré and Kühlewein editions as well as relevant CMG editions of the Hippocratic texts and of Galen's commentaries on these texts. A comparison of Arabic editions of Hippocratic writings with the present text showed that, with the exception of the Aphorisms, Hippocrates quotations often do not reproduce the exact wording as it appears in the Arabic editions. In almost all cases, however, they accurately reflect the sense of the quoted passages. Important or interesting variants have been entered into the apparatus.

\section{The English translation}

Many readers of this text will refer mainly or exclusively to the translation. One of its aims is therefore readability without, however, obscuring the distinct style and terminology of the Arabic version. This meant that the requirements of English style often had to be weighed against the desire to convey the particulars of the Arabic text as accurately as possible. Among the compromises these considerations imposed was that many of the abundant Arabic pronominal references that pick up previous referents and disambiguate the Greek text but that are unnecessary and cumbersome in English have been left out. Also, the Arabic use of the demonstrative pronouns "this" ( $h \bar{a} \underline{d} \bar{a} / h \bar{a} \underline{d} i h \bar{t})$ and "that" (d $\bar{a}$ lika/tilka) cannot always be mapped onto the English distinction between "this" and "that" without doing violence to the English language. In such cases the translation of these pronouns has been amended or they have been left out entirely. The footnotes to the translation occasionally supply explanatory remarks or literal English translations of Arabic phrases or passages where the translation itself strays from the literal meaning of the Arabic.

The translation also preserves the Arabic renderings of titles of Hippocratic, Galenic and other writings Galen referred to in his comments. Many are identical with the familiar forms that are in common use. Where the correlation is not immediately obvious, the Latin title is supplied in the footnotes to the translation.

The frequent incidence of synonymic doublets (hendiadys) and their purposes have been explained above. The English translation retains them to illustrate the 
style of the Arabic version and the translator's methods and technical terminology. They are indicated in the Notes to the translation.

Many key concepts of Hippocratic and Galenic medicine are rooted in an understanding of the human body and states of health and illness that is too far removed from our own medical frame of reference to be grasped easily. Translating them inevitably risks articulating them in terms that evoke modern medical notions and invite the reader to equate them with familiar symptoms and diseases. This issue is often discussed in the context of "retrospective diagnosis", the attempt to translate ancient descriptions of medical cases into modern diagnoses. ${ }^{1}$ Unsurprisingly, many such attempts to discover corresponding modern diseases have focussed on the Hippocratic Epidemics. ${ }^{2}$

The translation aims to avoid modern medical terminology. To reflect the vagueness that surrounds for example the various disease names ending in -ĩts ( $\rho \rho \varepsilon v \tilde{\imath} т 15, \sigma \pi \lambda \eta v \tilde{i} \tau$ เs, $\pi \lambda \varepsilon \cup \rho \tilde{i}$ trs etc.), their Arabic equivalents have been variously translated as disease of the spleen ( $\sigma \pi \lambda \eta \nu \tilde{i} t s)$, disease of the pleura ( $\pi \lambda \varepsilon \cup \rho \tilde{i} T 1 S)$ and so on. The translation of other elusive but central medical terms

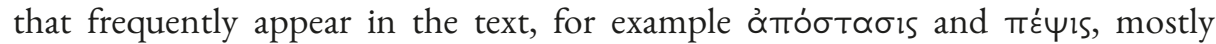
follows the lead of previous translators and authorities on ancient medicine. The by now substantial literature on Hippocratic terminology, especially studies of the vocabulary of the Epidemics, ${ }^{3}$ has been particularly helpful in this regard, as has the advice of colleagues in the field.

The Notes to the translation concentrate on philological issues and are meant to help understand and compare the Greek and Arabic texts. They mainly record conspicuous differences between the two versions, especially the frequent amplifications and additions inserted by the Arabic translator and a limited number of stylistic characteristics of the text. ${ }^{4}$ The categories of textual correspondences proposed by the editors of the GALex ${ }^{5}$ form the basis of the abbreviations employed to describe the nature of the relationship between given Arabic and Greek textual elements. They are as follows:

1 Cf. e.g. K.-H. Leven, 'At Times these Ancient Facts Seem to Lie Before Me Like a Patient On a Hospital Bed' - Retrospective Diagnosis and Ancient Medical History, in: Magic and Rationality in Ancient Near Eastern and Graeco-Roman Medicine, ed. by. H. F. J. Horstmannshoff and M. Stol, Leiden and Boston 2004 (Studies in Ancient Medicine 27), p. 369-386.

2 Cf. L. A. Graumann, Die Krankengeschichten der Epidemienbücher des Corpus Hippocraticum. Medizinhistorische Bedeutung und Möglichkeiten der retrospektiven Diagnose, Aachen 2000 (Berichte aus der Medizin).

3 Esp. P. Berrettoni, Il lessico tecnico del I e III libro delle Epidemie ippocratiche (Contributo alla storia della formazione della terminologia medica greca), Annali della Scuola Normale Superiore di Pisa. Lettere, Storia e Filosofia, serie II 39, 1970, p. 27-106, 217-311; S. Byl, Néologismes et premières attestations de noms de maladies, symptômes et syndromes dans le Corpus Hippocratique, in: Maladie et maladies. Histoire et conceptualisation, ed. by D. Gourevitch, Geneva 1992 (Hautes études médiévales et modernes 70), p. 77-94; and V. Langholf, Medical Theories in Hippocrates. Early Texts and the 'Epidemics', Berlin and New York 1990 (Untersuchungen zur antiken Literatur und Geschichte 34).

4 Page and line references to Wenkebach's Greek edition (CMG V 10,1) in the notes to the translation have been indicated with the abbreviation "Gr.".

5 Cf. GALex, p. 5*sq., 37*-42*. 
add. the Arabic translation adds textual elements that are neither expressed nor implied in the Greek version; ${ }^{1}$

amplif. the Arabic translation adds textual elements to amplify the meaning implicit in the Greek version; ${ }^{2}$

concentr. one Arabic textual element translates more than one Greek textual element;

def. the Arabic translator supplied a definition of a Greek textual element;

om. the Arabic translation omits a Greek textual element;

paraphr. a paraphrastic recasting of a Greek textual element that does not involve a change in meaning; ${ }^{3}$

periphr. a recasting of a Greek textual element with a circumlocution or periphrase that changes the meaning of the text; ${ }^{4}$

transpos. the reordering of Greek textual elements.

All of these modifications could have entered the text at different times in its complex translation and transmission history. Especially in the case of omissions it is very often impossible to determine whether the words in question had already been absent in the Greek source manuscript, whether they had been intentionally left out by the Syriac or Arabic translator or whether they have dropped out in the process of copying and re-copying the Arabic manuscript.

The Notes to the translation are not meant to be comprehensive; for example, they omit brief amplifications and repetitions of textual elements that were, in the interest of readability, shortened or eliminated in the English translation. It will also be immediately obvious that some categories necessarily overlap to some degree: depending on what the text of a given passage implies or not, a number of amplifications may also be interpreted as short additions; and the distinction between paraphrase and periphrase necessarily involves personal judgment.

For medical matters, the reader is invited to consult the extensive secondary literature on Hippocratic medicine, the Hippocratic Epidemics and Galen's commentary that are cited in this introduction and the notes to the translation. On Greek philological issues, the Wenkebach edition of the Greek text of the commentary and the reviews it occasioned are still the best starting points.

\section{Acknowledgments}

The edition and translation of an extensive and important ancient or medieval text is always a collaborative venture which depends heavily on feedback, criticisms and suggestions from many sides. This is particularly true for this work, which is the outcome of a multi-year team effort to produce the first editions and English translations of the Arabic versions of Galen's Commentary on Books 1 and 2 of the Hippocratic Epidemics, generously funded by the Wellcome Trust (grant no. WT084192MA). Members of the team (Simon Swain, Peter E. Pormann and Bink

\footnotetext{
1 See above, p. 53-55.

2 See above, p. 51-53.

3 Cf. GALex, p. $6^{*}$.

4 Cf. GALex, p. 6*.
} 
Hallum) read and commented on all or parts of the present text at different stages. Their feedback, in particular the extensive corrections and suggestions provided by the project's supervisor, Simon Swain, who proofread the current volume in its entirety, led to substantial improvements. It also profited greatly from the corrections and suggestions made by the project leader, head of research and advisory board of the Corpus Medicorum Graecorum and an anonymous referee.

I am also very grateful to the participants of the 2010 "Epidemics in Context" conference held at the Warburg Institute in London. Their input in the form of feedback on a draft text circulated in advance, conference papers and discussions has been invaluable. Special thanks go to Ivan Garofalo, who - in addition to the extensive notes on the Arabic translation of Galen's Commentary on Books 1 and 2 of the Hippocratic Epidemics which he published in the journal Galenos in $2009^{1}-$ read our draft edition, sent us additional detailed notes on the text and presented a paper on the textual problems of the Commentary on Book 2 at the London conference. The translation in particular also profited from the assistance we received from Christine Salazar, who helped us better to understand the terminology of the Greek version of the Commentary on Book 1 and made numerous valuable suggestions for English translations of medical terms.

While compiling the primary and secondary sources of the edition, the CMG project and its head, Roland Wittwer, provided crucial support by giving us access to the papers of Franz Pfaff; Gotthard Strohmaier advised us on formal matters; and the technical assistance offered by Florian Gärtner and Wolfram Brunschön was invaluable at the typesetting stage. Gerrit Bos, the editor of Maimonides' Medical Aphorisms, graciously sent us material quoted from the Commentaries on Books 1 and 2 contained in the still unpublished parts of this work. The director of the Escorial library, José Luis del Valle Merino, gave us a warm welcome and generous assistance on two visits to compare our transcripts with the unique manuscript of the present text, ms. E. Finally, Fabian Käs made two important Arabic secondary sources that were written on the basis of Hunayn's translations available to us. These texts gave us further important insights into the reception of Galen's commentary in the Islamic world. The support and encouragement of these and many other colleagues at various stages is gratefully acknowledged.

1 Garofalo, I commenti alle Epidemie. 
